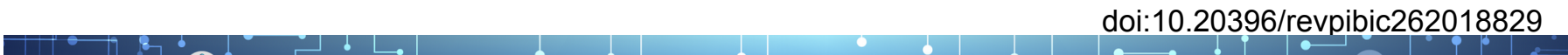

\section{Medida da Seção de Choque para Absorção de Dois Fótons pela Saturação da Fotoluminescência}

\author{
Leonardo W. T. Barros*, Gabriel Nagamine, Lázaro A. Padilha Jr.
}

\section{Resumo}

Foi estudado um método para determinar a seção de choque para absorção de dois fótons $(\delta)$ de um nanomaterial, obtendo a curva de saturação da fotoluminescência em relação à potência do laser incidente. Tal procedimento poderá ser utilizado para obter $\delta$ com menor erro propagado e, dessa forma, ajudar a compreender a estrutura de bandas de nanomateriais semicondutores.

\section{Palavras-chave:}

Óptica não-linear, Semicondutores, Nanomateriais

\section{Introdução}

Quando um nanomaterial é excitado por um laser com tempo de pulso curto o suficiente, dois fótons podem ser absorvidos simultaneamente, excitando um único elétron para estados de mais alta energia. A este fenômeno de óptica não-linear se dá o nome de absorção de dois fótons (2PA) ${ }^{1}$. Em nanomateriais semicondutores, como os pontos quânticos, quando ocorre a 2PA, um elétron da banda de valência se desloca para um estado mais energético, na banda de condução. Ao voltar para seu estado fundamental, ocorre a emissão de um fóton por parte do material. A luz emitida (fotoluminescência) é composta por fótons cujas energias podem ser, então, maiores do que as dos fótons incidentes ${ }^{2}$.

Neste trabalho, testamos um novo procedimento experimental para determinar a seção de choque $(\delta)$ para a 2PA de um nanomaterial para determinada frequência do laser incidente. Este procedimento leva em consideração o fato de que apenas excitons (um exciton é um par elétron-buraco) são altamente emissíveis, enquanto multi-excitons não emitem eficientemente.

Consideramos na elaboração deste trabalho que a absorção de dois fótons por parte de um material segue a estatística de Poisson ${ }^{3}$, e relacionamos $\delta$ à fotoluminescência, que será medida. Saturando a fotoluminescência da amostra, é possível determinar $\delta$.

\section{Resultados e Discussão}

A configuração do experimento foi feita de maneira a incidir um feixe de laser com potência alta o suficiente para saturar a emissão da amostra, isto é, fazer com que todos os pontos quânticos da amostra tenham realizado a absorção de pelo menos dois fótons.

Pela estatística de Poisson, sabemos que a probabilidade de $\mathrm{N}$ fótons serem absorvidos por um ponto quântico é de:

$$
P_{N}=\frac{e^{-\langle N\rangle}\langle N\rangle^{N}}{N !}
$$

Onde $\langle\mathrm{N}\rangle$ é o número médio de fótons absorvidos por ponto quântico, que é dado pela expressão em função da fluência de fótons incidentes $F$ e da largura de pulso do laser $(\mathrm{T})$ :

$$
\langle N\rangle=\frac{\delta . F^{2}}{\tau}
$$

$\delta$ é dada em GM ( $\mathrm{cm}^{4}$.s/fóton). Sabemos que a fotoluminescência por 2PA, que é o dado que coletaremos, é proporcional à probabilidade de 0 material absorver dois ou mais fótons. Para as potências que estamos trabalhando, consideramos que $P_{0}$ é desprezível. Assim, uma normalização da curva de saturação com base na estatística de Poisson nos permite determinar, a partir da amplitude do sinal medido, a seção de choque para 2PA de um material.

Elaboramos $O$ procedimento experimental utilizando um laser pulsado de femtossegundos com comprimento de onda de $800 \mathrm{~nm}$. O feixe passa por um filtro polarizador e uma placa de meia-onda que, juntos, podem ser ajustados para regular a potência do feixe. $\mathrm{O}$ feixe então incide na amostra, que está em uma cubeta de quartzo inserida em um porta-amostra. A fotoluminescência é coletada por um espectrômetro conectado a um computador.

Tendo montado o experimento, coletamos a coletamos a fotoluminescência da amostra para diferentes valores de potência do laser incidente.

\section{Conclusão}

Foi possível observar que a relação entre fotoluminescência e potência do laser incidente não era linear, como esperado para o caso de fotoluminescência por 2PA. O procedimento aqui estudado é capaz de determinar a seção de choque para 2PA de nanomateriais semicondutores. A vantagem deste método para outros já conhecidos, como o Z-Scan e a espectroscopia de fotoluminescência devido à 2PA, é a simplicidade e a menor propagação de erros.

\section{Agradecimentos}

Agradeço aos coautores deste trabalho Gabriel Nagamine e Lázaro Padilha, e à todo o grupo do laboratório de espectroscopia ultra-rápida (USL). Agradeço também à CNPQ por financiar este projeto.

\footnotetext{
${ }^{1}$ Kaiser, W.; Garret, C.G., "Two-Photon Excitation in CaF2: Eu²+ ”, Physical Review Letters, vol. 7, Issue 6, pp. 229-231 (1961)

${ }^{2}$ Blanton, S. A., Hines, M. A., Schmidt, M. E. \& GuyotSionnest, P. Two-photon spectroscopy and microscopy of II-VI semiconductor nanocrystals. Journal of Luminescence 70, 253-268 (1996).

${ }^{3}$ G.Nagamine, "Revelando a estrutura eletrônica de nanomateriais através de espectroscopia óptica avançada”, 2017.
} 